\title{
Integrated Large-Scale Environmental Information Systems: A Short Survey
}

\author{
Stavros Kolios, Olga Maurodimou, and Chrysostomos Stylios \\ Department of Informatics and Communications Technology, \\ Technological Educational Institution of Epirus, Arta, 47100 Greece \\ stavroskolios@kic.teiep.gr, \\ styliosateiep.gr
}

\begin{abstract}
The installation and operation of instrument/sensor networks has great importance in monitoring the physical environment from local to global scale. Nowadays, such networks comprise vital parts of integrated information systems that are called Environmental Information Systems (EIS). Such systems provide real time monitoring, forecasts and interesting conclusions extracted from the collected data sets that are stored in huge databases. These systems are used as the main source of data for model parameterization and as verification tools for accuracy assessment techniques. This paper comprises a short survey aiming to highlight the significant role of existing Environmental Information Systems (ELIS) consisted of instrument/sensor networks that are used for large-scale monitoring of environmental issues regarding atmospheric and marine environment. The operating principles of these systems, their usefulness, restrictions and their perspectives in the environmental sciences, are studied and described.
\end{abstract}

Keywords: Environmental Information Systems, Instrument/sensor networks.

\section{Introduction}

The role of the Environmental Information Systems (EIS) is widely accepted and known. Although there are many different definitions about EIS (Avouris and Page, 1995; Checkland and Holwell, 1998) all of them, share major common components in their architecture that include among others databases, monitoring modules, Geographical Information Systems (GIS) and the visualization of complex environmental data. In this study, we define as Environmental Information Systems (EIS) the integrated systems that use networks of instruments/sensors in order to collect and combine different kinds of data using automated procedures and providing high-quality products and services. These systems collect time-series of data and provide products at different spatial scales that are used to further monitor and forecast atmospheric, land and marine environment parameters as well as weather and climate changes. The most modern EIS uses indispensably, Environmental Sensor (or instrument) Networks (ESNs) as part of their structure because their installation and operation is proven fundamental for the monitoring of the physical environment. 
Thanks to recent technological advances in microelectronics, wireless communication technology and informatics, new advanced sensors have been emerged/evolved that are operating in clusters/arrays of devices utilizing wireless network. The development of sensor/instrumentation networks involves various research scientific fields, such as sensing, communication and computing areas (e.g. Chong and Kumar, 2009). These advances have led to the development of a huge number of networks at different spatial scales that measure, collect and store a wide range of environmental parameters. Nowadays, the modern ESNs are capable to record with high accuracy a wide variety of parameters in near real time and save the data for later recovery. There is a continuously increasing interest in ESNs establishment as modern networks have capabilities that geoscientists could hardly consider of twenty years ago. ESNs have been gradually evolved into integrated information systems that can be called EIS (according to the above mentioned definition) and provide real-time monitoring, forecasts and archive data of many different products and parameters from the initial collected data sets. The datasets of such systems are used as data sources to feed models with initial parameter values and as verification data pools for accuracy assessment of the satellite imagery. Another application area of EIS is in decision making, where along with other kinds of data (e.g. satellite data, socioeconomic parameters, census data) can provide an informational background in order to manage problems, suggest solutions and best practices for a sustainable management of the environment.

This work comprises a comparative study aiming to record and highlight the role of the existing EIS that use instrument/sensor networks along with other kinds of data for large-to-global scale monitoring of environmental issues of the atmospheric and the marine environment as well as weather and climate. There are examining characteristic examples of large scale instrument/sensor networks that are basic parts of EIS, where along with additional sources of data (like satellite datasets), are used as integrated information systems to measure, identify, monitor, analyse and forecast a vast series of atmospheric parameters (like $\mathrm{CO}_{2}, \mathrm{O}_{3}$, particle matter and solar irradiance), weather, climate and their impacts (e.g., cloud systems, lightning, rainfall, air and surface temperature, humidity, winds) and marine environment (salinity, water quality, sea surface temperature among others).

\section{Basic Operating Principles of Environmental Sensor Networks}

The ESNs can be separated into three general categories relating to the spatial scale: local, regional and global (Hart et al., 2006). The local scale networks tend to cover local and strictly defined regions, measuring specific parameters through a network of interconnected nodes, via like Radio Frequency (RF), internet or acoustic waves. The sensors are usually placed in space according to the scientific or operational needs. Any set of sensors- stand for a cluster that gathers measurements (Chong et al., 2003) where the sensors of a cluster form a particular topology either "star" or "peer-topeer" (Buratti et al., 2009). The types of sensors can be passive (e.g. acoustic, seismic, IR, magnetic) or active (e.g. radars, lidars) (Chong et al. 2003). There are also many different types of sensors according to the parameters, they record. The sensors are 
also categorized, in relation to their size, shape and their mobility because they can be stationary (e.g. seismic sensors), mobile (e.g. on robot vehicles) (Chong et al., 2003) and buoys (e.g. Forecast at sea, monitoring sea surface). Additionally, the communication among sensors can be wired, or wireless; using broadband or narrowband connectivity and the energy needed from each sensor is proportional to its size (Chong et al., 2003). In general, a cluster communicates with a server through a gateway, wireless or wired connection. The gateway is a network node equipped for interfacing with another network that uses different communication protocols. The way that information is transferred from the portal of the server differs, depending on the distance between them. When the distance is local, wired or wireless internet or RF signals for data transmission are used. If the distance gate to server is long enough, the transmission of information is achieved via satellite communication. The next "stop" of the information flow is the router. A router is a device that forwards data packets between computer networks, creating an overlay internetwork. The information comes out of the router and enters the server. In the most common use, a server is a physical computer (a computer hardware system) dedicated to run one or more services (as a host) and to serve the needs of the users of other computers on a network. The server then either sends the data collected from the sensors in a database that stores and keeps records for subsequent processes and investigations, or sends it to a user to further process them (Figure 1). There is an option to enter the data into a user interface for the information sent to the data station. User interfaces allow the users to handle the information of the system's database and visualize the selected data and products [graphical user interface (GUI)]. The last "stop" of the information flow in the network is a computer or a network of parallel-connected computers, which processes the total data available to the data station and those that might have been processed by the user or a user interface.

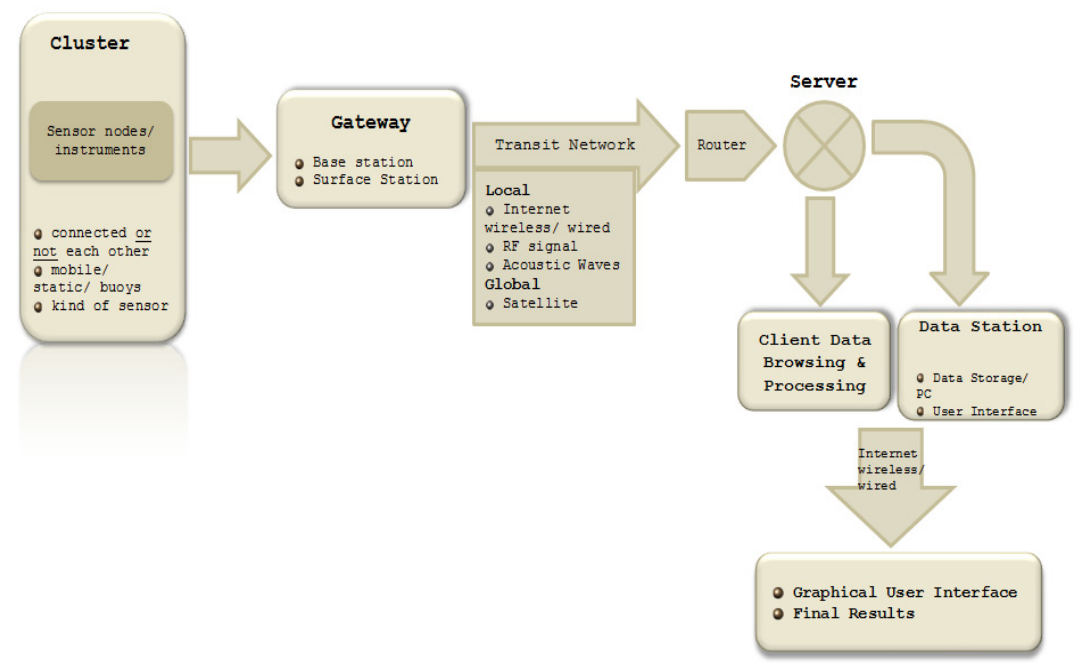

Fig. 1. A schematic flow chart of operation of environmental sensor networks 


\section{Examples of Existing Systems}

\subsection{Atmosphere}

The environmental sensor networks monitor phenomena in the atmosphere usually dealing with air quality and measure quantities of chemical compounds (organic and inorganic), greenhouse gases, dust and particle matters in the atmosphere. It is well known that the role of the atmosphere and the sun radiation is vital for the earth natural environment, the flora, the fauna and the human lives. Changes in the atmospheric components affect - among others - the incoming solar radiation, the upwelling radiation and finally the energy balance on the Earth with unpredictable consequences to weather, climate and sustainability of many species. Environmental Information Systems has been very important and can further improve our knowledge regarding the variations of atmospheric components at large up to global scale. Regarding the Table 1, the "EuNetAir" comprises a Cooperative network based on advanced chemical sensors and sensor-systems at low-cost, including functional materials and nanotechnologies for low-cost air-pollution monitoring through field studies and laboratory experiments, to transfer the results into preventive real-time control practices (Penza, 2012). The main scope of this network is a cleaner air in Europe with reduced negative effects; targeting to outdoor air pollution control and indoor energy efficiency in buildings. It fosters the technology of new sensing costeffective chemical sensors in the European countries (Penza, 2012).

Table 1. Examples of EIS that are referred to atmospheric parameters

\begin{tabular}{|c|c|c|}
\hline Name of the System & Parameters & Year \\
\hline Cost Action TD1105 - EuNetAir & $\begin{array}{l}\mathrm{CO}_{2}, \mathrm{H}_{2} \mathrm{O}, \mathrm{NOx}, \mathrm{SO}_{2}, \mathrm{H}_{2} \mathrm{~S} \\
\text { VOCs, PM, PAH, } \mathrm{O}_{3} \text {, etc. }\end{array}$ & 2011 \\
\hline EARLINET & aerosols & 2000 \\
\hline $\begin{array}{l}\text { GAPS (Global Atmospheric Passive Sampling } \\
\text { Network) }\end{array}$ & $\begin{array}{l}\text { Persistent organic pollutants } \\
\text { (POPs) }\end{array}$ & 2004 \\
\hline GAW - Global Atmosphere Watch & $\begin{array}{l}\text { e.g. greenhouse gases }\left(\mathrm{CO}_{2},\right. \\
\text { chlorofluorocarbons, } \mathrm{CH}_{4}, \mathrm{O}_{3} \text {, } \\
\left.\mathrm{N}_{2} \mathrm{O}, \mathrm{CO}, \mathrm{NO}_{x}, \mathrm{SO}_{2}, \mathrm{VOC}\right) \\
\text { ozone, } \mathrm{UV} \text {, aerosols }\end{array}$ & 2012 \\
\hline
\end{tabular}

Another noteworthy system is the "EARLINET" (Table 1). This system is an aerosol lidar network, established in 2000, with the main goal to provide a comprehensive, quantitative, and statistically significant data base for the aerosol distribution on a European scale. Because of the unpropitious effects of aerosols on human life, it is important to achieve an advanced understanding of the processes that generate, redistribute, and remove aerosols in the atmosphere, through EARLINET system that has the capability for accurate and timely measurements and monitoring. The "GAPS" Network refers specifically to Persistent Organic Pollutants (POPs) in 
air (e.g. Breivik et al., 2002). Measurements of POPs are integrated with other to assess temporal trends and for investigating regional and long-range transport of POPs and other priority chemicals (e.g Breivik et al., 2002). The "GAPS" project initiated at 2004 in global-scale and it is operating currently at more than 50 sites around the world. Reliable scientific data and information on the chemical composition of the atmosphere and its natural and anthropogenic changes are measured and monitored through cooperation among institutions and organizations of many countries worldwide, within the "GAW" (Global Atmosphere Watch) program (e.g. Plass-Dülmer et al., 2002). To achieve the programme's goals, a network of hundreds of instruments and sensors are used all around Earth. It is mentioned that some of collected datasets of the "GAW" network are coupled with satellite measurements, which results in a more complete picture of atmospheric composition and processes on global scale that provides complimentary checks of instrument calibrations. Summarizing, "EARLINET" is a system focused on aerosols that are measured using a network of lidars. In opposite, the "EuNetAir" system uses many different types of sensors and networks, combining many different data and parameters of a wide variety of atmospheric components including aerosols. Another focused network in a specific category of components is the "GAPS" network that is referred as above mentioned to the POPs. Finally, the "GAW" programme can be included in the category of "system of systems" because uses many different data sets from many different systems worldwide, having as objective to collect data and products from many different sources for a better understanding and monitoring of the atmosphere and the marine environment.

\subsection{Marine Environment}

The EIS for the marine environment monitor and deal with a plethora of data and parameters that extends even in meteorology. The sensors of these systems are being designed to have the ability to measure physical, chemical and biological parameters that control the marine life. Phytoplankton, water temperature, optical depth, deposition of particle matter and chemical compounds, turbidity and height of waves are only just some of the parameters that these network systems monitor.

The "GOOS" is a collection of ocean observing and information delivery system ("system of systems") for observations, modeling and analysis of marine and ocean variables to support operational ocean services worldwide (e.g. Worth et al., 2001). This system provides high-quality descriptions of the present state of the oceans, including living resources, continuous forecasts of the future conditions of the sea for as far ahead as possible, and the basis for forecasts of climate change. Satellite instruments, free floating buoys and profilers are used - among others - in order to measure parameters like sea surface temperature, salinity etc.

The "IOCCP" comprises (e.g. Telszewski, 2012) a global network for the development of globally acceptable strategies, methodologies, practices and standards, homogenizing efforts of the research community as well as integrating ocean carbon programs and activities aiming at a sustained global observation network for marine biogeochemistry. 
Table 2. Examples of EIS regarding to the marine environment

\begin{tabular}{|c|c|c|}
\hline Name of the System & Parameter & Year \\
\hline $\begin{array}{c}\text { GOOS - Global Ocean Observing } \\
\text { System }\end{array}$ & $\begin{array}{l}\text { e.g. temperature, salinity, } \\
\text { atmospheric pressure, oxygen, carbon } \\
\text { dioxide }\left(\mathrm{CO}_{2}\right)\end{array}$ & 1991 \\
\hline $\begin{array}{l}\text { IOCCP - International Ocean } \\
\text { Carbon Coordination Project }\end{array}$ & $\begin{array}{l}\text { Dissolved organic carbon, alkalinity, } \\
\mathrm{pCO}_{2}, \mathrm{pH} \text {, particulate carbon }\end{array}$ & 2005 \\
\hline $\begin{array}{l}\text { NOOS - North West European } \\
\text { Shelf Operational Oceanographic } \\
\text { System }\end{array}$ & $\begin{array}{l}\text { e.g. tides, storm surges, mean sea } \\
\text { level change, surface temperature, } \\
\text { salinity, dissolved oxygen, nutrients, } \\
\text { chlorophyll }\end{array}$ & 2006 \\
\hline
\end{tabular}

The "NOOS" system is aiming to develop and implement online operational marine data and information, to provide analysis, forecasts, and model-based products describing the marine conditions and to establish a marine database that proves time series and statistical analyses (Holt, 2003). Main measured parameters include discharged loads, water level, waves and sea surface temperature. The forecasted parameters include total water net transports, seal level and wind currents.

Summarizing, the "GOOS" system is fully autonomous, having its own observation networks that provide a global view of the ocean system. It comprises a network system of sub-systems, each of which is working on different and complementary aspects of establishing an operational ocean observation capability. It is consisted of many different observation platforms that measure initial data in order to collect, monitor, describe and forecast the state of the oceans.

The "IOCCP" system on the other hand, has one clear objective, the ocean carbon observations. It's a global scale system that focuses on specific ocean parameters.

Finally, the "NOOS" system is a large scale system that covers the European North West Shelf (NWS), providing reliable descriptions of the actual marine conditions on the NWS area, through many different kinds of variables about the specific marine environment. The system has its own instrumentation network and its final scope is to develop and implement ocean observing and prediction services for the NWS area, by delivering real time operational data and products.

At this point, it is mentioned that there are some similar systems to "NOOS", like Baltic Operational Oceanographic System ("BOOS") and others that operate in regional scale and their data are used from broader scale systems such as GOOS that belongs to the category of "system of systems".

\section{Conclusions}

This study comprises a short review regarding the Environmental Information Systems that use indispensably instrumentation/sensor networks in order to collect environmental information. There are described the main basic operating principles and then it focuses on EIS for Atmosphere and Marine Environment; providing basic knowledge about the parameters that they record and the services that they provide. 
We present systems that operate in the large to global scale and we have mentioned that at global scale there is an approach to combine many systems that are established at regional and large scale. The combined use of regional and large scale systems and their recorded parameters can be further integrated into central databases that provide with the philosophy of a global information system, valuable information, products and services at global scale. The integration of information from many different regional/large systems to a central "global nature" system can define this, as "system of systems". Additionally, there is an increasing tendency to develop such systems by unifying smaller scale ones and creating global monitoring systems for a better understanding of Earth's environment.

The EIS uses instrumentation/sensor networks that record and process simultaneously vast types of parameters in large-to-global scale, associated with the atmosphere, the climate and the marine environment. The technological advances in many fields like sensing, telecommunications and computing can be integrated with the geosciences, resulting in fully automated systems that can record, collect and store a wide variety of parameters. The initially measured data and parameters can be further analyzed providing many valuable final products and services. The large scale monitoring systems can operate not only as databases but also as monitoring and forecasting systems, providing with this way plenty of services to the end users according to the goals and the needs for wide environmental issues. It is mentioned that EIS can provide a wealth of information not only to science but in public too, through data sending to decision making and risk management systems. This is another important contribution of such systems with beneficial effects to the sustainability of the environment as well as the quality of human lives, properties and their economic activities. We have also to mention, that such systems can help importantly to a sustainable and environmentally correct of the reindustrialization in local up to national and international level, through planning and management of air and water pollutants.

Acknowledgements. This work was supported by the "Transnational enhancement of ECOPORT 8 network" (TEN ECOPORT) project with code SEE/D/ 0189/ 2.2/X. project co-financed by the European Union within the South East Europe Transnational Cooperation Program.

\section{References}

1. Avouris, N.M., Page, B.: Environmental Informatics: Methodology and Applications of Environmental Information Processing. Kluwer Academic, Dordrecht (1995)

2. Checkland, P., Holwell, S.: Information, Systems and Information System -Making Sense of the Field. John Wiley \& Sons Ltd., Chichester (1998)

3. Chong, C.-Y., Kumar, S.P.: Sensor Networks: Evolution, Opportunities, and Challenges. Proceedings of the IEEE 91(8), 1247-1256 (2003)

4. Hart, J.K., Martinez, K.: Environmental Sensor Networks: A revolution in the earth system science? Earth-Science Reviews 78, 177-191 (2006)

5. Buratti, C., Conti, A., Dardari, D., Verdone, R.: An Overview on Wireless Sensor Networks Technology and Evolution. Sensors 9, 6869-6896 (2009) 
6. Penza, M.: Overview oft he COST Action TD 1105 EuNet0Air. In: IMCS 2012 - The 14th International Meeting on Chemical Sensors, Nuremberg, German (May 20-23, 2012)

7. Breivik, K., Sweetman, A.J., Pacyna, J., Jones, M., Kevin, C.: Towards a global historical emission inventory for selected PCB congeners - a mass balance approach. I. Global Production and Consumption. Science of the Total Environment 290(1-3), 181-198 (2002)

8. Plass-Dülmer, C., Michl, K., Ruf, R., Berresheim, H.: C2 -C8, Hydrocarbon measurement and quality control procedures at the Global Atmosphere Watch Observatory Hohenpeissenberg. Journal of Chromatography A 953, 175-197 (2002)

9. Telszewski, F.: International Ocean Carbon Coordination Project Progress Report for SCOR, IOC/SCOR International Ocean Carbon Coordination Project, IOCCP (2012)

10. Holt, M.: Towards NOOS-the EuroGoos new shelf task team 1996-2002. Elsevier Oceanography Series 69, 461-465 (2003)

11. Nowlin Jr., W.D., Briscoe, M., Smith, N., McPhaden, M.J., Roemmich, D., Chapman, P., Grassle, J.F.: Evolution of sustained ocean observing system. Bulletin of the American Meteorological Society 82, 1369-1376 (2001) 